\title{
November 2013 Phoenix Pulmonary Journal Club: Pleural Catheter Infection
}

\author{
Fysh ET, Tremblay A, Feller-Kopman D, Mishra EK, Slade M, Garske L, \\ Clive AO, Lamb C, Boshuizen R, Ng BJ, Rosenstengel AW, Yarmus L, \\ Rahman NM, Maskell NA, Lee YC. Clinical outcomes of indwelling pleural \\ catheter-related pleural infections: an international multicenter study. \\ Chest. 2013;144(5):1597-602. [CrossRef] [PubMed]
}

Tunneled indwelling pleural catheters (TPC) have revolutionized the treatment of recurrent malignant pleural effusions. Malignant pleural effusions are seen in up to $15 \%$ of advanced malignancies such as lung and breast cancer. Prior to the approval of TPC, treatment options were limited to mechanical or chemical pleurodesis. The FDA approved the use of TPC for the treatment of malignant pleural effusions (MPE) in 1997. The study published by Putnam, Light et al. (1) validated the use of tunneled pleural catheters in the management of malignant pleural effusions. Over the last decade the use of TPC has escalated. This retrospective study looks at the number of reported cases of tunneled pleural catheter related infections.

The study was a retrospective chart review of done through 11 centers from the years 2001-2012. A total of 1021 patients and catheters were placed during this time frame for the management of MPE. Catheter related infections were defined by having bacteria or pus present in the pleural fluid, having signs and symptoms of infection and the need for antibiotics. The study also identified what the common pathogens were and how infections were managed.

The results showed that the rate of TPC infections were low at 4.9\% (50 cases). The median duration from time of catheter insertion until infection was 62 days. The most common pathogen was methicillin sensitive Staphylococcus aureus (48\%) followed by gram negatives (18\%). The majority of the patients (37patients) required admission to the hospital for intravenous antibiotics while the others were treated in the home setting. The median duration of antibiotic administration was 24 days. Intra-pleural fibrinolytics were used in 13 patients and 23 patients had their TPC removed. None of the patients required surgery and there were 3 deaths attributed to infection of the TPC.

This large retrospective cohort study yields the largest collection of data on infection rates in the setting of TPC. There are several limitations to the study but the main one is the lack of identifying drainage technique and place. In our practice setting we have noted no TPC infections over the last 5 years when drainage was performed by a home health nurse or within the office setting. We have noted an increased incidence of TPC infections when drainage was done by the patients themselves or by family members. The study does reinforce that TPC remain a safe and less invasive way to manage MPE. Infections are not that common and in most cases can be managed with antibiotics alone. 
Manoj Mathew, MD FCCP MCCM

\section{Reference}

1. Putnam JB Jr, Light RW, Rodriguez RM, Ponn R, Olak J, Pollak JS, Lee RB, Payne DK, Graeber G, Kovitz KL. A randomized comparison of indwelling pleural catheter and doxycycline pleurodesis in the management of malignant pleural effusions. Cancer. 1999;86(10):1992-9. [CrossRef] [PubMed] 